\title{
DESTINAÇÃO FINAL DE RESÍDUOS SÓLIDOS: ENFOQUE GEOTÉCNICO AO ATERRO SANITÁRIO DE PRESIDENTE VENCESLAU/SP
}

\section{FINAL DESTINATION OF SOLID WASTE: GEOTECHNICAL FOCUS ON SANITARY LANDFILL OF PRESIDENTE VENCESLAU/SP}

${ }^{1}$ José Guilherme Marques Chitero, ${ }^{2}$ Lucas Prado Osco

Universidade do Oeste Paulista - UNOESTE, ${ }^{1}$ Especialização em Gestão de Projetos e Processos, ${ }^{2}$ Mestrado em Meio Ambiente e Desenvolvimento Regional, Presidente Prudente, SP.

E-mail: guilhermechitero@live.com

RESUMO - O presente trabalho apresenta a discussão referente as condições geotécnicas que devem ser consideradas em um aterro de resíduos sólidos, utilizando como estudo de caso o aterro sanitário de Presidente Venceslau - SP, apontando as condições averiguadas na área do empreendimento. Para tanto, a pesquisa foi desenvolvida por meio de vistorias em campo e pareceres técnicos sobre o aterro sanitário municipal de Presidente Venceslau - SP. Observar e identificar as características geotécnicas do empreendimento instalado e de possíveis impactos às condições dos recursos naturais, como o lençol freático da região e solo no qual o aterro encontra-se instalado. Buscando analisar estudos e dados que corresponde a estrutura do aterro, sua influência dentro da bacia hidrográfica em que se encontra, bem como da geologia local. Os resultados indicaram má gestão do empreendimento, riscos reais de contaminação do lençol freático e instabilidade geotécnica, uma vez que o funcionamento do aterro sanitário se encontra comprometido em razão das características apresentadas.

Palavras-chave: Geotécnica; Geotecnia Ambiental; Impacto; Resíduos Sólidos; Aterro Sanitário; Destinação Final.

ABSTRACT - This paper presents a discussion regarding the geotechnical conditions that must be considered in a solid waste landfill, using as a case study the landfill Wenceslas President - SP, pointing out the conditions investigated in the project area. Therefore, the research was developed through surveys in the field and technical advice on the municipal landfill Wenceslas President - SP. Observe and identify the geotechnical characteristics of the installed project and possible impacts to the conditions of natural resources such as groundwater and soil in the area where the landfill is installed. Trying to analyze studies and data that matches the structure of the site, its

Recebido em: 19/08/2015 Revisado em: 09/09/2015 Aprovado em: 15/09/2015 influence within the watershed in which it is as well as the local geology. The results indicated poor management of the enterprise, actual contamination of groundwater and geotechnical instability risks, 
since the operation of the landfill is compromised due to the characteristics presented.

Keywords: Geotechnical; Environmental Geotechnics; Impact; Landfill Site; Final Destination. 


\section{INTRODUÇÃO}

Devido à crescente urbanização dos últimos anos, cresce cada vez mais a preocupação em relação a destinação final dos resíduos sólidos gerados pela população, promovendo, assim, práticas que reduzam a quantidade, bem como os danos ocasionados pela destinação final desses resíduos. Dentre os modos de destinação final, o aterro sanitário consiste-se em uma das mais bem aceitas formas de disposição. A seleção de áreas para a implantação de aterros sanitários requer um corpo técnico preparado para o empreendimento, resultando em uma tarefa que demanda estudos aprofundados nas áreas de geotecnia, geologia, ambiental e estrutural (MARQUES, 2002).

A utilização de critérios para a seleção de um local apropriado parte da economia até as características dos resíduos sólidos que serão depositados no aterro. Aterros sanitários, quando bem construídos (ou seja, atendendo as especificações mínimas como a impermeabilização da base e a presença de drenos para coletado lixiviado), operados com eficiência (com cobertura de solo ao final de cada período de serviço) são alternativas seguras para a deposição dos resíduos (OLIVEIRA; PASQUAL, 2004). Outro risco em potencial são as instabilidades geotécnicas em aterros que possuam características específicas, como disposições em pilhas elevadas ou em pontas de aterro. Para tanto, o presente trabalho atribui um enfoco à essas condições geotécnicas, que devem ser consideradas durante a destinação final de resíduos sólidos em aterros sanitários. Para isso realizou-se um estudo de caso ao aterro sanitário de resíduos sólidos de Presidente Venceslau SP, apontando as condições averiguadas na área do empreendimento e suas consequências locais.

\section{METODOLOGIA}

\section{Localização e Características Gerais da Área} de Estudo

O aterro situa-se no município de Presidente Venceslau, localizado a oeste do Estado de São Paulo, pertencente a bacia hidrográfica do rio Santo Anastácio, com coordenada central de Latitude de $21^{\circ} 55^{\prime} 24.21^{\prime \prime} \mathrm{S}$ e Longitude de $51^{\circ} 51^{\prime} 27.50^{\prime \prime} \mathrm{O}$,e área de aproximadamente 96.800m² (SEADE, 2004). A área apresenta uma topografia pouco inclinada, por onde se tem acesso por uma vicinal asfaltada, cercada por propriedades rurais na maioria voltadas para a atividade de pecuária. A nascente mais próxima do aterro se encontra a aproximadamente 400 metros, pertence ao córrego do Fortuna. O centro urbano da cidade de Presidente Venceslau depara-se a cerca de 4 quilômetros do depósito. 
Com clima subtropical AW, de acordo com a classificação Köppen-Geiger, o aterro sanitário foi construído em formato de trincheiras, apresenta geologia local predominante composta por rochas sedimentares da bacia do Paraná, de idade mesozoica. Essas rochas são classificadas dentro do Grupo Bauru, pertencentes à Formação Adamantina (Ka) e Formação Santo Anastácio (Ksa) (SUIZU; ROCHA, 2011). Sua geomorfologia acompanha à estrutura regional, com as camadas sub-horizontais apresentando um leve caimento para o oeste (SILVA; ALVARES, 2005). Os tipos de solos presentes no município de Presidente Venceslau dividem-se entre quatro classes pedológicas: o Podzólico vermelho escuro (Pve); Podzólico vermelho amarelo (Pve, Pva); Latossolo vermelho escuro (Lea) e Glei (HGP) (COOPERATIVA DE SERVIÇOS E PESQUISAS TECNOLÓGICAS E INDUSTRIAIS, 1999). A Figura 1 apresentada abaixo procura ilustrar a localidade do aterro em contraste com o município de Presidente Venceslau.

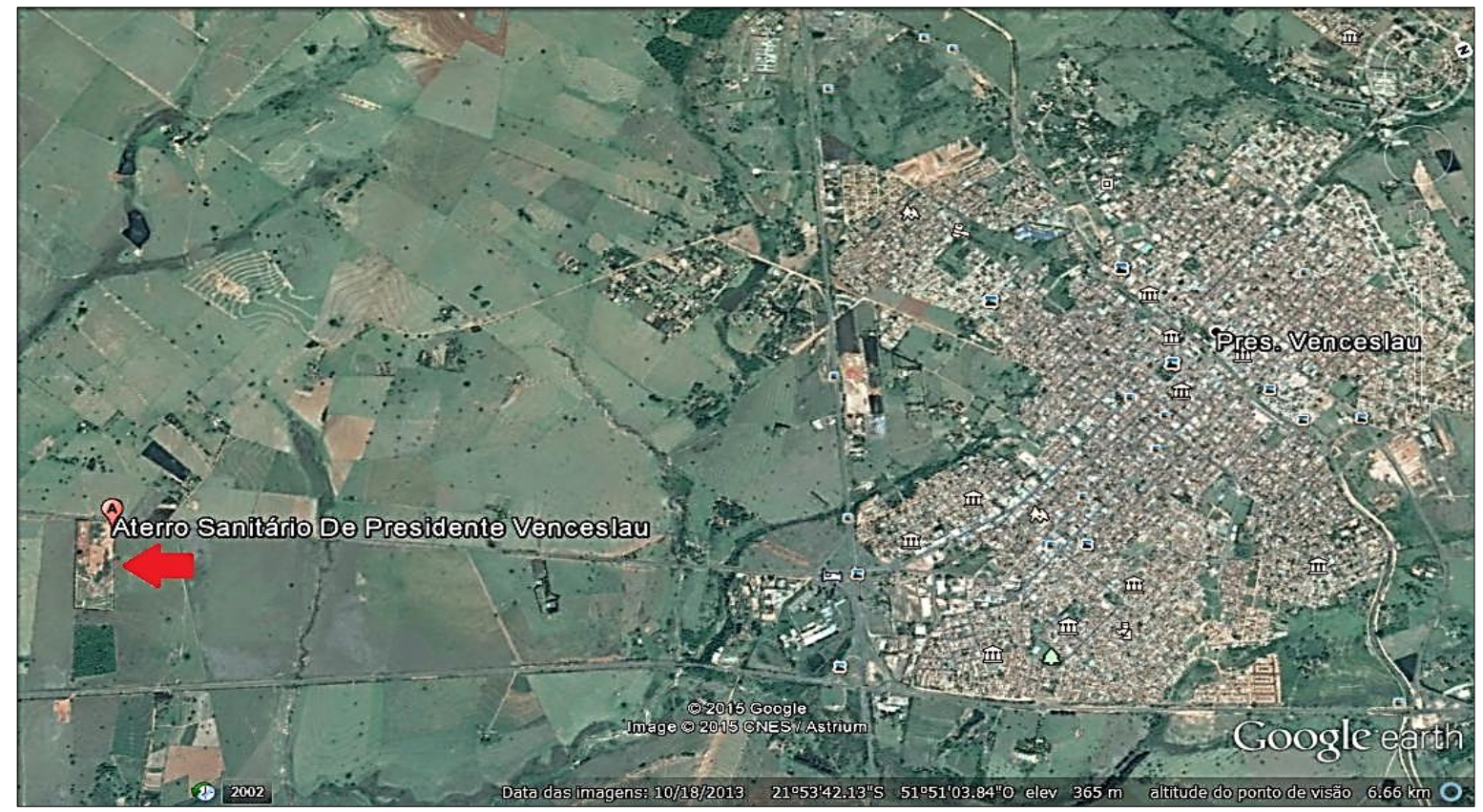

Figura 1. Localização Aterro Sanitário de Presidente Venceslau/SP (Google Earth) em 2013.

Procedimento Adotado na Averiguação de

\section{Dados Locais}

Esta etapa foi elaborada, inicialmente, através de um levantamento bibliográfico referente as características geotécnicas e geológicas de aterros sanitários, resíduos sólidos e área de implantação de aterro. Para tanto embasou-se principalmente nos trabalhos de (SOUZA, 2002; SUIZU; ROCHA, 2011; MARQUES, 2002; LEITE, 1995), dentre outros. Posteriormente realizou-se, a partir da compilação de pareceres técnicos sobre o aterro sanitário de Presidente Venceslau - SP (SÃO PAULO. Ministério Público de São Paulo 
(2004-2012). Sendo assim, uma vez elencada as principais características da área, bem como compreendido os laudos técnicos desenvolvidos durante as vistorias desenvolvidas pelo Ministério Público, deu-se início a constatação em campo das informações obtidas, com o intuito de comprovar a adequabilidade ou irregularidade do aterro de resíduos sólidos estudado.

\section{RESULTADOS}

Segundo o parecer técnico $N^{\circ} 001 / 04-$ Venceslau, sondagens foram realizadas no maciço do aterro; no qual se obtiveram três furos de sondagens, perfurando um montante de 37,31 metros de sondagens com coleta de 37 amostras; e seis covas para ensaios de permeabilidade com profundidade média de dois metros. Essas análises detiveram como enfoque principal a resistência à penetração e permeabilidade do solo local.

Os testes de permeabilidade determinaram valores de coeficiente de permeabilidade (Cp) entre média e alta infiltração, tendo como base o nível de superfície do solo. Em média o coeficiente de infiltração (Ci) encontrado foi de 67,75 litros $/ \mathrm{m}^{2} \mathrm{x}$ dia, provando que haverá alta percolação de líquidos sobre o maciço do aterro; a Tabela 1 a seguir mostra a classificação do solo de acordo com a taxa de percolação no mesmo.

Tabela 1. Tabela de classificação do solo de acordo com o coeficiente de infiltração de acordo com a NBR 7229-1993.

\begin{tabular}{|c|c|c|}
\hline Faixa & Constituição provável dos solos & $\begin{array}{l}\text { Coeficiente de Infiltração } \\
\qquad / \mathrm{m}^{2} x \text { dia }\end{array}$ \\
\hline 1 & $\begin{array}{l}\text { Rochas, argilas compactadas, variando a rxs alteradas e argilas compactadas } \\
\text { avermelhadas. }\end{array}$ & Menor que 20 \\
\hline 2 & $\begin{array}{l}\text { Argilas de cor amarela, vermelha ou marrom medianamente compacta, } \\
\text { variando a pouco siltosas e/ou arenosas. }\end{array}$ & 20 a 40 \\
\hline 3 & $\begin{array}{l}\text { Argilas arenosas e/ou siltosas, variando a areia ou silte argiloso de cor } \\
\text { amarela, vermelha ou marrom. }\end{array}$ & 40 a 60 \\
\hline $\begin{array}{l}4 \\
5\end{array}$ & $\begin{array}{l}\text { Areia ou silte argiloso, ou solo arenoso com húmus e turfas, variando a solos } \\
\qquad \text { de areias e siltes }\end{array}$ & 60 a 90 \\
\hline 6 & Areia bem selecionada e limpa, variando a área grossa com cascalho. & Maior que 90 \\
\hline
\end{tabular}

Fonte: (Associação Brasileira de Normas Técnicas, 1993) 
Conforme a Tabela acima, o solo do aterro é classificado em areno-argiloso, ou seja, ocorre alta percolação do efluente gerado. Assim, a impermeabilização do fundo da trincheira é primordial para o bom funcionamento do aterro além de evitar a poluição do lençol freático e uma possível instabilidade geotécnica do talude (SUIZU; ROCHA, 2011). Ainda assim, um aterro sanitário deve contar com um monitoramento constante de suas condições, justamente para evitar problemas que, sejam por má geotecnia ou mau gerenciamento, possam ocasionar impactos ambientais na área de disposição dos resíduos.

Entretanto, durante as visitas conduzias ao local, no ano de 2014, foi possível observar um atendimento precário aos parâmetros necessários. A Figura 2 apresentada logo a seguir denuncia o chorume vazado e percolado por entre a massa de resíduos que, ao encontrar a camada impermeabilizadora por baixo da vala escavada, acumula-se no local, causando o entupimento dos poços de captação de gás metano.

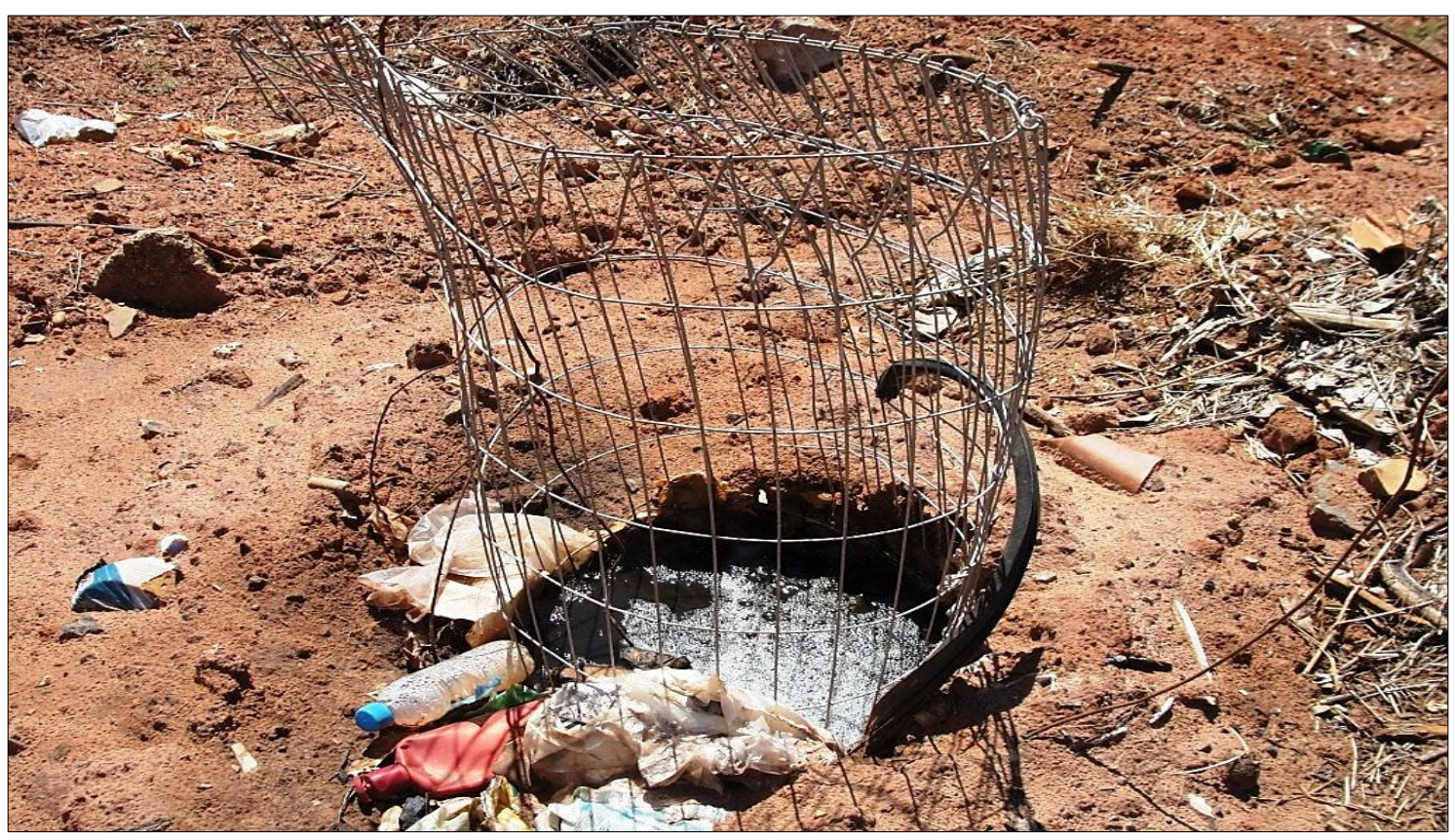

Figura 2. Chorume entupindo o poço de captação no aterro de Presidente Venceslau em 2014.

Em área próxima à anterior pôde-se comprovar outra consequência da acumulação mencionada. Em porções mais baixas da vala preenchida, com leve declive no terreno, observaram-se afloramentos de chorume, especialmente quando o solo se encontrava compactado por maquinários mais pesados (Figura 3). 


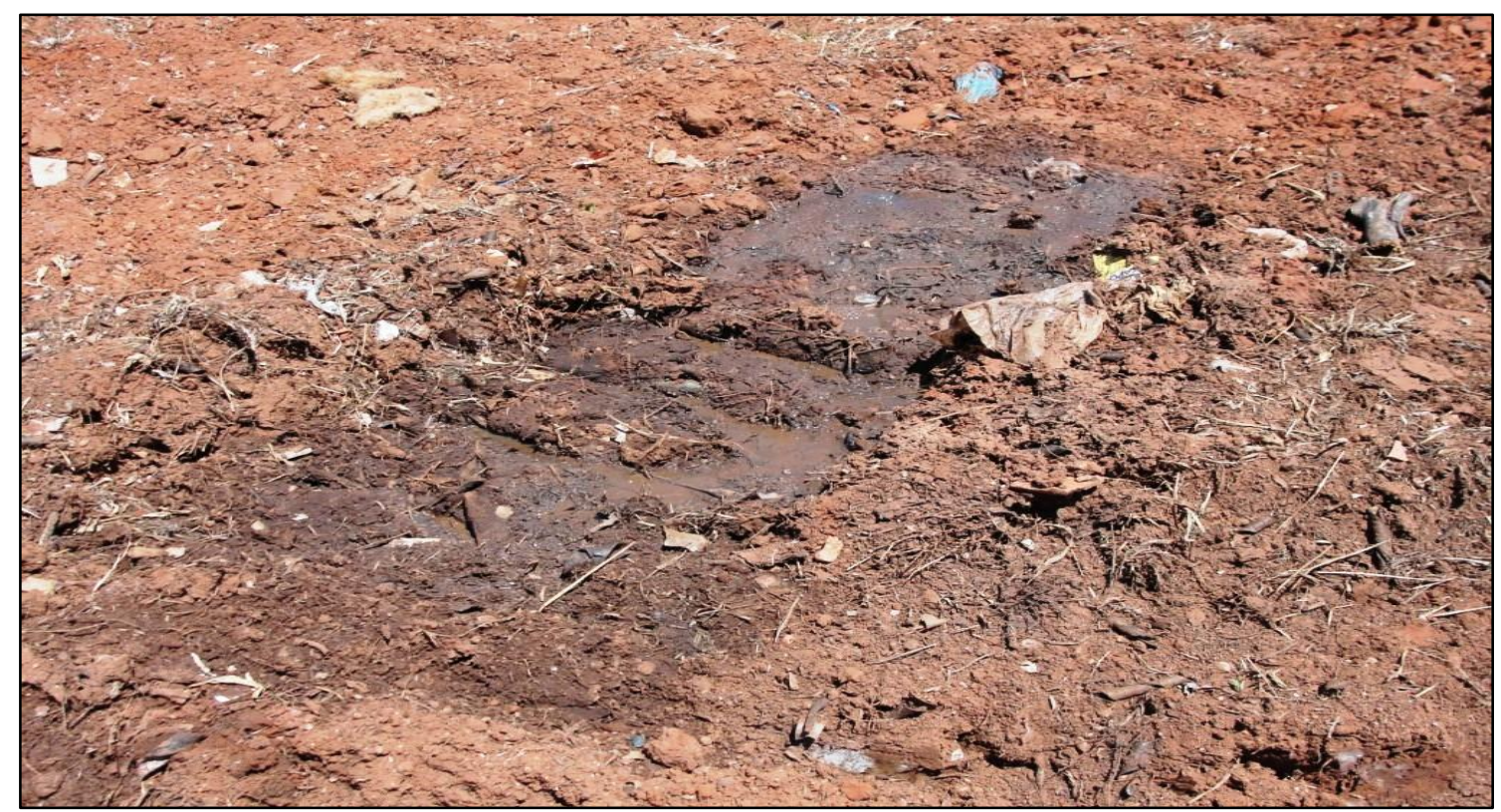

Figura 3. Chorume aflorando na superfície de vala no aterro de Presidente Venceslau em 2014.

Outra condição averiguada na área foi a instabilização de taludes em locais anteriores à abertura das valas para o aterro sanitário. Essas antigas áreas, recobertas de lixo, estavam sendo escavadas novamente com o intuito de direcionar os resíduos compactados previamente às valas impermeabilizadas (Figura 4). Ainda assim, em razão das características do solo, bem como da própria instabilidade da massa de resíduos, a parte escavada oferece sérios riscos aos trabalhadores envolvidos no processo de remoção e transporte dos materiais. 


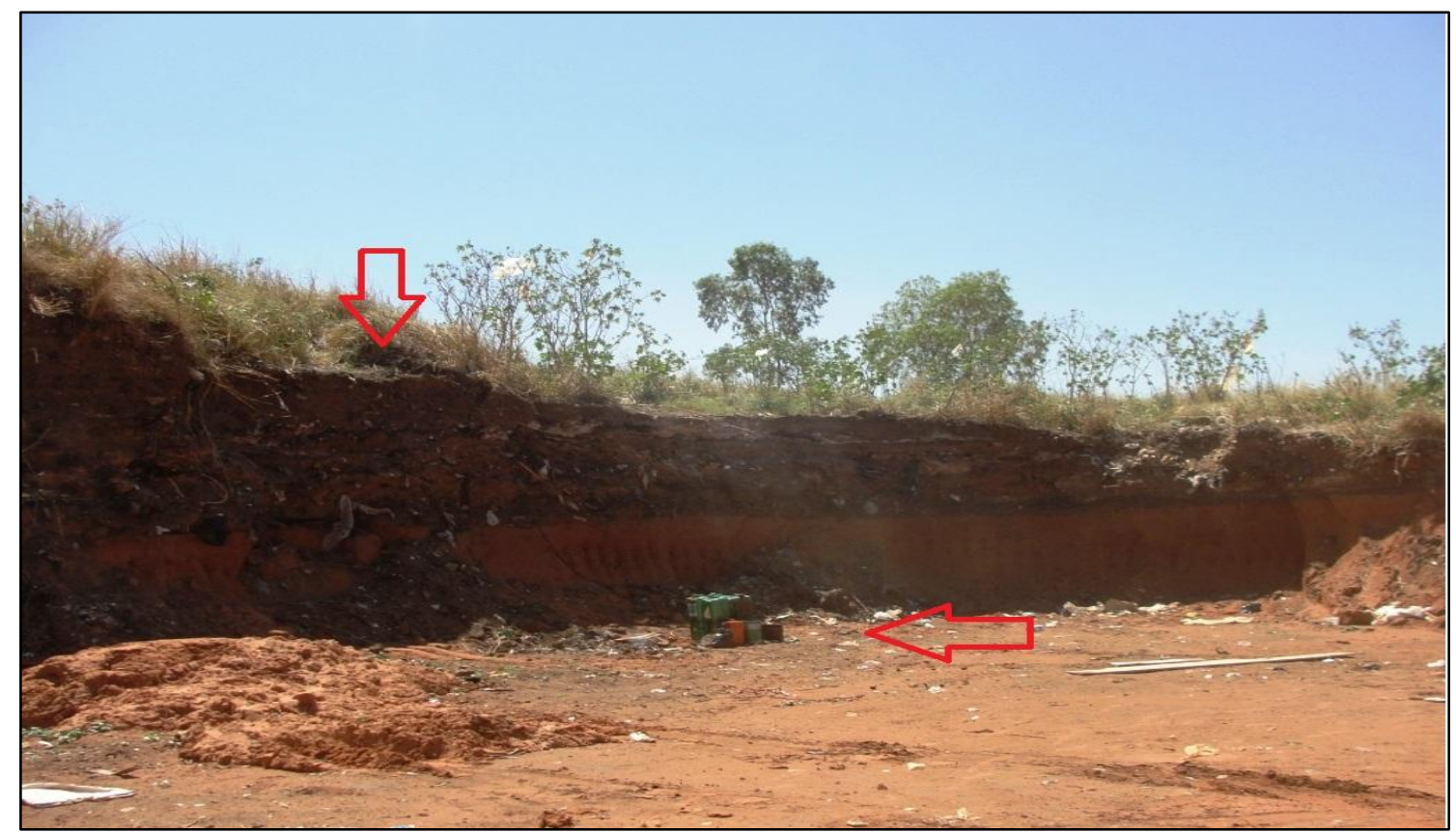

Figura 4. Talude geotécnicamente instável e resíduo sólido depositado a céu aberto no aterro de Presidente Venceslau em 2014.

\section{DISCUSSÃO}

Entende-se que o chorume presente em aterros venha a conter elevados níveis de ácidos orgânicos, amônia e sólidos totais dissolvidos. Não obstante, grande parte da massa biodegradada é fragmentada com o tempo (FARQUHAR, 1989). O problema, contudo, se faz na possibilidade de o chorume conter substâncias tóxicas e perigosas que, ao infiltrar por entre as camadas de solo, possa atingir zonas de corpos d'água subterrâneos, inviabilizando o uso deste recurso hídrico. O biogás, por sua vez, controlado inibi a instabilidade do aterro, pois minimiza a migração desses gases para áreas adjacentes, ocasionando infiltrações nos sistemas de esgoto, melhorando o bem-estar das populações vizinhas ao aterro, justamente devido a redução dos odores produzidos pela emissão de mercaptanas e compostos com enxofre (SÃO PAULO. Companhia Estadual de Saneamento Ambiental, 1997).

O aterro sanitário de Presidente Venceslau (SP) possui um sistema de drenagem de gás metano e de chorume, contendo uma lagoa de armazenamento do liquido, bem como apresentando o fundo das valas impermeabilizado. Essas características garantiram a classificação do aterro como sanitário pelo órgão ambiental. Contudo, conforme o que pôde ser observado a partir dos resultados expostos, as condições de operação do empreendimento revelam a má gestão realizada na área. A rede coletora de chorume, devido a drenagem irregular do 
liquido, conteve o contaminante sobre suas mantas, o que permitiu a acumulação e ascensão do chorume, extravasando a trincheira e adentrando-se nos drenos de gases. Essas condições, somada à presença de animais, catadores, queimadas e demais ocorrências observadas no local garante ao aterro sua irregularidade (embora não reconhecida pelo IQR, 2014, realizado pelo órgão ambiental, a CETESB, durante o mesmo período das visitas).

\section{CONCLUSÃO}

Um dos maiores problemas enfrentados atualmente pela sociedade moderna são gerados pelo aumento da produção de resíduos sólidos e, consequentemente, sua destinação final. 0 estudo geotécnico e ambiental da locação do empreendimento se torna um importante instrumento no auxílio à preservação ambiental do ecossistema ao redor do aterro. Sendo assim, algumas sugestões para os problemas constatados durante os trabalhos realizados visam manter a vida útil do aterro, tais como:

- Desobstruir a rede de drenagem que se encontra entupida, permitindo livrar o chorume acumulado na vala e deixar os drenos de biogás livres para a passagem do gás produzido, queimando-os;
- Corrigir os taludes instáveis com técnicas de engenharia e continuar a destinar os resíduos para as trincheiras impermeabilizadas;

- Aplicar monitoramento geotécnico e ambiental periodicamente da área, evitando futuras falhas estruturais e de funcionamento do aterro.

Não obstante, o principal fator para o estado estrutural e técnico que se encontra o aterro de Presidente Venceslau se faz pelo mal gerenciamento local. A maioria dos problemas poderiam ser facilmente evitados por um maior cuidado daqueles que são considerados responsáveis pela manutenção, bem como por visitas periódicas do órgão ambiental responsável por sua fiscalização.

\section{REFERÊNCIAS}

Associação Brasileira de Normas Técnicas. NBR 7229. Projeto, construção e operação de sistemas de tanques sépticos. Rio de Janeiro: ABNT, 1993.

COOPERATIVA DE SERVIÇOS E PESQUISAS TECNOLÓGICAS E INDUSTRIAIS. Relatório Zero da bacia hidrográfica do Pontal do Paranapanema. São Paulo: CPTI, 1999.

LEITE, J. C. Metodologia para elaboração da carta de susceptibilidade à contaminação e poluição das águas superficiais. 1995. 192p. Dissertação (Mestrado) - Escola de Engenharia de São Carlos, Universidade de São Paulo, São Carlos -SP. 
MARQUES, G. N. Seleção de áreas para aterros sanitários baseada em mapeamento geotécnico e analytichierarchyprocess

(AHP). 2002. 163p. Dissertação (Mestrado) Escola de Engenharia de São Carlos, Universidade de São Paulo, São Carlos - SP.

OLIVEIRA, S.; PASQUAL, A. Avaliação de parâmetros indicadores de poluição por efluente liquido de um aterro sanitário.

Engenharia Sanitária e Ambiental, v. 9, n. 3, p. 240-249, 2004.

http://dx.doi.org/10.1590/S1413-

41522004000300010

SÃO PAULO. Companhia Estadual de Saneamento Ambiental. Aterro em valas. São Paulo: CETESB, 1997. (apostilas ambientais).

SÃO PAULO. Ministério Público de São Paulo. Parecer técnico sobre aterro sanitário de Presidente Venceslau. 2004-2012.

SILVA, A.M.; ALVARES, C.A. Levantamento de informações e estruturação de um banco de dados sobre a erodibilidade de classes de solos no Estado de São Paulo. Geociências, 2005.

SUIZU, T.M.; ROCHA, P.C. Modificações Na Morfologia Da Planície Fluvial Do Rio Santo Anastácio-Sp. Periódico Eletrônico

Fórum, 2011. 